\title{
Scientific publications in nursing journals from Mainland China, Taiwan, and Hong Kong: a 10-year survey of the literature
}

Di Zhang, Xiaming Wang, Xueru Yuan, Li Yang, Yu Xue, Qian Xie

Background: China has witnessed remarkable progress in scientific performance in recent years. However, the quantity and quality of nursing publications from three major regions (Mainland China, Taiwan, and Hong Kong) have not been reported. This study aimed to investigate the characteristics of scientific research productivity from Mainland China, Taiwan, and Hong Kong in the field of nursing. Methods: Articles published in the 110 nursing journals originating from Mainland China, Taiwan, and Hong Kong between 2005 and 2014 were retrieved from Web of Science. The total number of articles published, the impact factor, and the citation count were analyzed. Results: There were 2,439 publications between 2005 and 2014 from China, including 438 from Mainland China, 1,506 from Taiwan, and 495 from Hong Kong. There was a significant increase in publications for these three regions $(p<0.05$ ), especially for Mainland China, with a 59.50fold increase experienced. From 2011, the number of publications from Mainland China exceeded that from Hong Kong. Taiwan had the highest total journal impact factor $(2,142.81)$, followed by Hong Kong (720.39) and Mainland China (583.94). The mean journal impact factor from Hong Kong (1.46) was higher than that from Taiwan (1.42) and Mainland China (1.33). Taiwan had the highest total citation count $(8,392)$, followed by Hong Kong $(3,785)$ and Mainland China $(1,493)$. The mean citation count from Hong Kong (7.65) was higher than that from Taiwan (5.57) and Mainland China (3.41). The Journal of Clinical Nursing was the most popular journal in the three regions. Discussion: Chinese contributions to the field of nursing have significantly increased in the past ten years, particularly from Mainland China. Taiwan is the most productive region in China. Hong Kong had the highest-quality research output, according to mean journal impact factor and mean citation count. 
1 Scientific publications in nursing journals from Mainland China, Taiwan, and Hong Kong:

2 a 10-year survey of the literature

3 Di Zhang ${ }^{1}$, Xiaming Wang ${ }^{2}$, Xueru Yuan ${ }^{1}$, Li Yang ${ }^{1}$, Yu Xue ${ }^{1}$, and Qian Xie ${ }^{1}$

$4{ }^{1}$ Department of Anesthesiology, Navy General Hospital, Beijing, China.

$5 \quad 2$ Department of Otorhinolaryngology, Navy General Hospital, Beijing, China.

7 Di Zhang, Xiaming Wang, and Xueru Yuan contributed equally to this work as co-first authors.

8

9 Corresponding Authors:

10 Qian Xie $^{1}$

11 NO. 6 Fucheng Road, Beijing 100048, China

12 Email address: xieqiannavy@163.com

$13 \mathrm{Yu} \mathrm{Xue}^{1}$

14 NO. 6 Fucheng Road, Beijing 100048, China

15 Email address: xueyunavy@163.com

16

17

18

19

20

21

22

23 


\section{Abstract}

26 Background: China has witnessed remarkable progress in scientific performance in recent years.

27 However, the quantity and quality of nursing publications from three major regions (Mainland

28 China, Taiwan, and Hong Kong) have not been reported. This study aimed to investigate the 29 characteristics of scientific research productivity from Mainland China, Taiwan, and Hong Kong 30 in the field of nursing.

31 Methods: Articles published in the 110 nursing journals originating from Mainland China, 32 Taiwan, and Hong Kong between 2005 and 2014 were retrieved from Web of Science. The total 33 number of articles published, the impact factor, and the citation count were analyzed.

34 Results: There were 2,439 publications between 2005 and 2014 from China, including 438 from 35 Mainland China, 1,506 from Taiwan, and 495 from Hong Kong. There was a significant increase 36 in publications for these three regions $(\mathrm{p}<0.05)$, especially for Mainland China, with a 59.5037 fold increase experienced. From 2011, the number of publications from Mainland China 38 exceeded that from Hong Kong. Taiwan had the highest total journal impact factor $(2,142.81)$, 39 followed by Hong Kong (720.39) and Mainland China (583.94). The mean journal impact factor 40 from Hong Kong (1.46) was higher than that from Taiwan (1.42) and Mainland China (1.33).

41 Taiwan had the highest total citation count $(8,392)$, followed by Hong Kong $(3,785)$ and 42 Mainland China (1,493). The mean citation count from Hong Kong (7.65) was higher than that 43 from Taiwan (5.57) and Mainland China (3.41). The Journal of Clinical Nursing was the most 44 popular journal in the three regions.

45 Discussion: Chinese contributions to the field of nursing have significantly increased in the past 46 ten years, particularly from Mainland China. Taiwan is the most productive region in China. 
47 Hong Kong had the highest-quality research output, according to mean journal impact factor and

48 mean citation count.

49

50 INTRODUCTION

51 China is a rapidly progressing developing country, with a population of over 1.3 billion people.

52 In this context of rapid economic development, China has played an increasing role in medicine 53 and science in the recent decades (Tong et al., 2013; Cyranoski, 2004; Ding et al., 2015; Liang

54 et al., 2015; Luo et al., 2015). A similar trend has also been observed with China's contribution

55 to nursing research (Li et al., 2009; Li et al., 2014; Kalisch \& Kalisch, 2009). Moreover, there

56 are more than 2 million registered nurses in China (Gao et al., 2012). China may become an

57 important hub in worldwide nursing research, given the emerging status and large community of

58 practitioners found in the country.

59 There are three major Chinese-speaking regions: Mainland China, Taiwan, and Hong Kong.

60 Although people in these regions share the same ethnic origin of Han Chinese, they have distinct

61 political regimes, economic status, and health care systems (Xu et al., 2000; Lin et al., 2014).

62 These characteristics may lead to different scientific research productivity outputs in these

63 regions. Publication, as a central part of scientific research, is an important indicator of research

64 productivity. Recently, it has been widely used to compare the scientific productivity of these

65 three regions in many medical fields (Gao et al., 2008; Li et al., 2010; Zheng et al., 2011; Cheng

$66 \&$ Zhang, 2010). However, as far as we are aware, the quantity and quality of nursing research

67 production in these Chinese-speaking regions have not yet been reported. Therefore, the present

68 study aimed to investigate the characteristics of scientific publications in the field of nursing 
69 from the major Chinese-speaking regions, specifically Mainland China, Hong Kong, and Taiwan, 70 over a ten-year period.

71

72 MATERIALS AND METHODS

73 Search strategy

74 The present study was designed based on methodology of previous similar articles (Gao et al., 75 2008; Li et al., 2010; Zheng et al., 2011; Cheng \& Zhang, 2010). In June 2015, the Web of 76 Science Core Collection was used to carry out a computerized search in order to identify nursing 77 publications. There are 110 subspecialty nursing journals listed under the "Nursing" category of 78 the 2014 Journal Citation Report (JCR). To include all articles published in the 110 nursing 79 journals, the titles of the journals were placed in the search window using the "OR" operator. The 80 study period was limited to 2005-2014. The refine panel of Web of Science was used to identify 81 articles. The filter of "Country/Region" was used to firstly sort the articles published by different 82 regions. We then selected "Peoples R China" or "Taiwan." Thus, articles originating from China 83 between 2005 and 2014 in these journals were identified. The filter of "Document types" was 84 then used to further refine the results. Only original articles and reviews were included. Letters,

85 editorial material, and corrections were excluded. The search output was exported to Microsoft 86 Office Excel for further analysis. The "Reprint Address" for each article was considered as the 87 source region (Zheng et al., 2011). Articles with are print address located in Mainland China, 88 Taiwan, and Hong Kong were selected accordingly.

89

Data extraction 
91 Two reviewers independently conducted the study selection and data extraction. The title and the

92 abstract of potentially eligible articles were reviewed. Articles unrelated to nursing topics were

93 further excluded. Disagreements were resolved by discussion. Number of publications was used

94 to evaluate the quantity of research output. The quality of research productivity was assessed

95 through two indicators: journal impact factor and citation count of articles. The impact factor

96 was obtained from the 2014 JCR. A region's total impact factor of published papers was

97 calculated by multiplying each journal's impact factor by the number of articles contained within

98 the publication. From articles originating in Mainland China, Taiwan, and Hong Kong, the

99 following information was collected: the total number of articles, the total and mean journal

100 impact factor, the total number of citations and mean citation count per article, articles published

101 in the top ten high-impact journals, and the five most popular journals in the three regions.

102 Journal popularity in a region was defined according to the number of articles published by

103 authors from this region: the more the articles, the more popular the journal.

105 Statistical analysis

106 Descriptive statistics (e.g. totals and means) are mainly used in this study. Regression analysis

107 was used to determine relationships between the quantities of articles published, and time trends

108 from 2005 to 2014. Data were analyzed with SPSS version 19.0 (SPSS Inc., Chicago, IL, USA)

109 and a significance threshold of 0.05 .

110

111 RESULTS

112 Total number of articles 
113 From the 110 nursing journals assessed between 2005 and 2014, a total number of 2,439

114 publications originated from China. The annual total numbers of articles from China increased

115 significantly from 2005 to 2014 (from 105 to $364 ; \mathrm{p}=0.000$ ), with a 3.47-fold increase

116 experienced. Taiwan published the largest number of articles in this time $(1,506 / 2,439 ; 61.75 \%)$,

117 followed by Hong Kong (495/2,439; 20.30\%) and Mainland China (438/2,439; 17.96\%). Figure

1181 shows the published articles from Mainland China, Hong Kong, and Taiwan. Mainland China

119 had the most rapid increase in the number of annual publications (from 2 to $119 ; \mathrm{p}=0.000$ ),

120 which is a 59.50-fold increase, followed by Taiwan (from 68 to 195; $p=0.001$ ) and Hong Kong

121 (from 35 to 50; $\mathrm{p}=0.017$ ). From 2011, the number of papers published from Mainland China

122 exceeded those from Hong Kong; however, Mainland China had fewer publications than Taiwan.

123

124 Journal impact factor

125 According to the 2014 JCR (Table 1), the total journal impact factor of Taiwan's published 126 papers $(2,142.81)$ was higher than that of Hong Kong (720.39) and Mainland China (583.94).

127 However, Hong Kong had the highest mean journal impact factor, at 1.46, followed by Taiwan 128 (1.42), and Mainland China (1.33) (Table 1). The impact factor of the journals publishing articles 129 from Mainland China was between 0.220 and 2.901; the range for Taiwan was from 0.000 to 130 2.901; and Hong Kong was between 0.439 and 2.901.

131

132 Citation count

133 Taiwan had a higher citation count of publications between 2005 and 2014 than Hong Kong 134 (3,785) and Mainland China (1,493) (Table 2). However, Hong Kong had the highest mean 
135 citation count per article (7.65), followed by Taiwan (5.57), and Mainland China (3.41) (Table 2).

136

137

138 High-impact worldwide nursing journals

139 In the $2014 \mathrm{JCR}$, the journal impact factor of ten high-impact worldwide nursing journals in

140 which Chinese authors published their work was greater than 1.7 (Table 3). Mainland China,

141 Taiwan, and Hong Kong had a total of 627 publications appear in these ten high-impact journals

142 between 2005 and 2014. Among these journals, Journal of Advanced Nursing had the highest

143 number of articles (256), followed by International Journal of Nursing Studies (191), and

144 Cancer Nursing (100). Taiwan published the largest number of papers (392) in the ten high-

145 impact journals, followed by Hong Kong (149) and Mainland China (86).

146

147 Popular nursing journals

148 The five most popular journals in the field of nursing for China are shown in Table 4. Journal of

149 Clinical Nursing was the most popular journal in all three regions, with 74 articles originating 150 from Mainland China, 392 articles from Taiwan, and 146 articles from Hong Kong. Journal of

151 Clinical Nursing, Journal of Advanced Nursing, International Journal of Nursing Studies, and

152 Cancer Nursing appeared in all top five journals across all three regions. Nurse Education Today

153 was found in the top five journal list in two regions. Journal of Nursing Research appeared in the 154 top five journal list in one region.

155

156 DISCUSSION 
157 To our knowledge, this is the first study to analyze the quantity and quality of articles in major

158 nursing journals that have been published from three major Chinese regions, namely Mainland

159 China, Taiwan, and Hong Kong, during a ten-year period. This survey provides a general picture

160 of Chinese research output in the field of nursing. This study revealed that China became

161 increasingly productive from 2005 to 2014 in major nursing journals, particularly Mainland

162 China. Scientific production in the field of nursing from Mainland China exceeded output from

163 Hong Kong since 2011. Taiwan is the most prolific region in China. However, Hong Kong

164 published the highest-quality nursing research, according to the analysis of mean journal impact

165 factor, and mean citation count per paper.

166 China's increasing contribution to scientific research has been demonstrated in many

167 biomedical fields (Gao et al., 2008; Li et al., 2010; Zheng et al., 2011; Cheng \& Zhang, 2010).

168 This also holds true for the field of nursing, according to the present findings. Although

169 Mainland China has lagged behind Taiwan and Hong Kong in terms of scientific productivity for

170 many years, since 2011, scientific research production in the field of nursing from Mainland

171 China has exceeded production from Hong Kong (Gao et al., 2008; Li et al., 2010; Zheng et al.,

172 2011; Cheng \& Zhang, 2010). Furthermore, the most rapid increase in the number of nursing

173 publications was seen in articles emanating from Mainland China. There are several possible

174 reasons for these findings. First, a central reason may be the rapid development of China's

175 economy, which has induced increased funding to the field of nursing (Kalisch \& Kalisch, 2009;

176 Gao et al., 2012). Second, Chinese nursing researchers have more experience than before, and

177 the ability of nurses in conducting research has been improved (Li et al., 2014; Kalisch \&

178 Kalisch, 2009; Gao et al., 2012). Third, high-level research institutions are increasingly being

179 established in China, and the education level of nursing is rapidly rising (Kalisch \& Kalisch, 
180 2009; Gao et al., 2012). The improvement of research infrastructure and the quality of

181 researchers may have prompted the high-level research output observed in this study. Fourth,

182 language has previously constituted an important barrier for most Chinese nursing researchers.

183 However, with increasing international knowledge-exchange, more authors from China have

184 recently published their work in international journals, thanks to increased English proficiency,

185 and developments in the experience of medical research (Cheng et al., 2012; Jia et al., 2015;

186 Tong et al.,2013). For these reasons, China will be able to contribute more to scientific

187 publication in the field of nursing.

188 Although China has increasing contributions to the field of nursing, several current problems

189 facing the discipline should be recognized. First, shortages of nurses are a global problem, and

190 China faces a severe shortage (Zeng, 2009). Nurses in China may lack sufficient time to perform

191 high-quality research. Second, although nursing education in China has developed rapidly, the

192 overall level of nursing education is still relatively low, requires improvement (You et al., 2015).

193 Having said this, these problems are being addressed in China (Zeng, 2009; You et al., 2015). It

194 is hoped that, through medical reforms, the status of nursing research in China will be improved

195 in the future (Chen et al., 2009; Liu et al., 2009).

196 In this study, journal impact factor and citation count were selected as measures, as they have

197 been widely used to evaluate the quality of articles, as seen in similar studies (Gao et al., 2008;

198 Li et al., 2010; Zheng et al., 2011; Cheng \& Zhang, 2010). Taiwan has the largest numbers of

199 total journal impact factor and total citation count among the three regions, indicating that it is

200 the most influential region in China. This could be due to Taiwan having the highest number of

201 total articles, far exceeding those from the other two regions. However, Hong Kong ranks the

202 first among the three regions when mean journal impact factor and mean citation count are used. 
203 It may suggest that Hong Kong published higher-quality nursing research than Mainland China

204 and Taiwan did. Moreover, Mainland China has the lowest mean journal impact factor and mean

205 citation count. These findings indicate that, despite the rapid increase in the number of

206 publications from Mainland China, articles from this region may be of lower quality and require

207 improvement, compared to those from Taiwan and Hong Kong. Nevertheless, it should be

208 recognized that the optimal tool for assessing the quality of publications remains controversial.

209 The impact factor is intended to assess the quality of a journal, but not the quality of an

210 individual article published in the journal (Li et al., 2010; Grzybowski, 2009). In general, the

211 impact factors of the journals in which the articles were published suggested similar academic

212 levels (Lin et al., 2011). Additionally, citation count may not be evenly distributed amongst

213 articles in a journal, as a small number of articles would probably attract the bulk of citations

214 (Weale et al., 2004; Seglen, 1997). Moreover, the citations for an article are highly related to the

215 quality of the article and the novelty of the findings. However, the number of citations is

216 influenced by many factors, such as journal impact factor, geographic origin of the authors,

217 whether they are English speaking, and the gender of the authors (Eyre-Walker, 2013; Paris et

218 al., 1998; Opthof, 1997; Leimu \& Koricheva, 2005).

219 Journal of Clinical Nursing was the most popular nursing journal in all the three regions. This

220 result indicates that Journal of Clinical Nursing is the most influential journal in China. Journal

221 of Clinical Nursing, Journal of Advanced Nursing, International Journal of Nursing Studies, and

222 Cancer Nursing appeared in all top five journals listings in the three regions. It suggests that

223 these journals may play an important role in promoting nursing research from China in

224 knowledge-sharing efforts. 
225 This study has some limitations. First, the data of another region in China, Macau, was 226 collected, but the present study did not analyze it due to the low number of articles originating

227 from this region. Second, the Web of Science database was used to identify nursing publications.

228 Articles published in journals not cited in Web of Science were not included, although they 229 might contribute to quantifying scientific production. Third, there is still no consensus on the 230 indicators for assessing the quality of articles. The use of journal impact factor and citation count 231 might not have been optimal in assessing some of the included articles. Fourth, although each

232 included article was published in nursing journals, some articles may have other topics as their 233 focus. Fifth, the journals were collected from the nursing category of the JCR, but 234 multidisciplinary journals may also publish articles related to nursing, and such journals were not 235 included in this study. Nevertheless, the 110 subspecialty nursing journals included in this survey 236 represent the major international journals devoted to the discipline of nursing.

237

238 CONCLUSION

239 There has been a significant increase in contributions to the field of nursing from China in the

240 past decade, particularly from Mainland China. Taiwan is the most prolific publication region in

241 China. Hong Kong had the highest-quality research outputs in terms of mean journal impact

242 factor and mean citation count per article.

244 Funding

245 There were no sources of funding for this study.

246 Competing interests

247 All authors declare there are no competing interests. 


\section{ACKNOWLEDGEMENTS}

250 We would like to thank our colleges for their help on this study.

251

\section{REFERENCES}

253 Chen Z (2009) Launch of the health-care reform plan in China. Lancet 373:1322-1324.

254 Cheng $\mathrm{T}$ (2012) Research in orthopaedics from China has thrived over the last decade: a 255 bibliometric analysis of publication activity. Orthop Traumatol Surg Res 98:253-258.

256 Cheng T, Zhang X (2010) Growing trend of China's contribution to the field of rheumatology 257 2000-2009: a survey of Chinese rheumatology research. J Rheumatol 37, 2390-2394.

258 Cyranoski D (2004) China increase share of global scientific publications. Nature 431, 116.

259 Ding F, Jia Z, Liu M (2015) National representation in the spine literature: a bibliometric 260 analysis of highly cited spine journals. Eur Spine J Aug 30. [Epub ahead of print].

261 Eyre-Walker A (2013) The assessment of science: the relative merits of post-publication review, 262 the impact factor, and the number of citations. PLoS Biol 11:e1001675.

263 Gao LL, Chan SW, Cheng BS (2012) The past, present and future of nursing education in 264 the People's Republic of China: a discussion paper. J Adv Nurs 68, 1429-1438.

265 Gao R, Liao Z, Li ZS (2008) Scientific publications in gastroenterology and hepatology journals 266 from Chinese authors in various parts of North Asia: 10-year survey of literature. $J$ 267 Gastroenterol Hepatol 23, 374-378.

268 Grzybowski A (2009) The journal impact factor: how to interpret its true value and importance. 269 Med Sci Monit 15, SR1-SR4. 
270 Jia ZW, Wu YH, Li H, Li HF, Zhao XY, Tang Y, Yao CL, Zhao YC, Liu LG, Wang de L, He Q,

271 Ruan DK (2015) Growing trend of China's contribution to the field of spine: a 10-year

$272 \quad$ survey of the literature. Eur Spine J 24,1806-1812.

273 Kalisch BJ, Kalisch Y (2009) Comparison of nursing: China and the United States. Nurs

$274 \quad$ Econ 27, 322-331.

275 Leimu R, Koricheva J (2005) What determines the citation frequency of ecological papers?

276 Trends Ecol Evol 20:28-32.

277 Li M, Wei L, Liu H, Tang L (2009) Integrative review of international nursing research in 278 Mainland China. Int Nurs Rev 56, 28-33.

279 Li X (2014) New opportunity for the development of nursing in China. J Nurs Scholarsh 46, $280 \quad 145-146$.

281 Li XQ, Tao KM, Zhou QH, Ling CQ (2011) Scientific Publications from Mainland China, 282 Taiwan, and Hong Kong in integrative and complementary medicine journals: a ten-year 283 literature surgery. Am J Chin Med. 39:639-649.

284 Li Z, Shi J, Liao Z, Wu FX, Yang LQ, Yu WF (2010) Scientific publications in anesthesiology 285 journals from mainland China, Taiwan, and Hong Kong: a 10-year survey of the literature. 286 Anesth Analg 110, 918-921.

287 Liang Z, Luo X, Gong F, Bao H, Qian H, Jia Z, Li G (2015) Worldwide research productivity in 288 the field of arthroscopy: a bibliometric analysis. Arthroscopy 31, 1452-1457.

289 Lin YH, Li J, Shieh SI, Kao CC, Lee I, Hung SL (2014) Comparison of professional values 290 between nursing students in Taiwan and China. Nurs Ethics Dec 18. pii: $291 \quad$ 0969733014561912. [Epub ahead of print].

292 Liu Y (2009) Reforming China's health care: for the people, by the people?. Lancet 373:281-283. 
293 Luo X, Liang Z, Gong F, Bao H, Huang L, Jia Z (2015) Worldwide productivity in the field of 294 foot and ankle research from 2009-2013: a bibliometric analysis of highly cited journals. $J$ $295 \quad$ Foot Ankle Res 8, 12.

296 Opthof T (1997) Sense and nonsense about the impact factor. Cardiovasc Res 33:1-7.

297 Paris G, De Leo G, Menozzi P, Gatto M (1998) Region-based citation bias in science. Nature $298 \quad 396: 210$.

299 Seglen PO (1997) Why the impact factor of journals should not be used for evaluating research. $300 \quad B M J 314: 498-502$.

301 Tong D, Wang L, Jiang J (2013) Publications from China in The Lancet, NEJM, and JAMA. $302 \quad$ Lancet $381,1983$.

303 Weale AR, Bailey M, Lear PA (2004) The level of non-citation of artilces within a journal as a 304 measure of quanlity: a comparison to the impact factor. BMC Med Res Methodol 4: 14.

$305 \mathrm{Xu} \mathrm{Y,} \mathrm{Xu} \mathrm{Z,} \mathrm{Zhang} \mathrm{J} \mathrm{(2000)} \mathrm{The} \mathrm{nursing} \mathrm{education} \mathrm{system} \mathrm{in} \mathrm{the} \mathrm{People's} \mathrm{Republic} \mathrm{of} \mathrm{China:}$ 306 evolution, structure and reform. Int Nurs Rev 47, 207-217.

307 You LM, Ke YY, Zheng J, Wan LH (2015) The development and issues of nursing education in 308 China: a national data analysis. Nurse Educ Today 35, 310-314.

309 Zeng Y (2009) Review of work-related stress in mainland Chinese nurses. Nurs Health Sci 11, $31090-97$.

311 Zheng ML, Yang LL, Shen Y, Shu Q (2011) Publications in ISI-indexed public health journals 312 from mainland China, Hong Kong and Taiwan during 1999-2008. Med Sci Monit 17, SR21$313 \quad$ SR27.

314 
320

321

322

323

324

325

326

327

328

329

330

331

332

333

334 


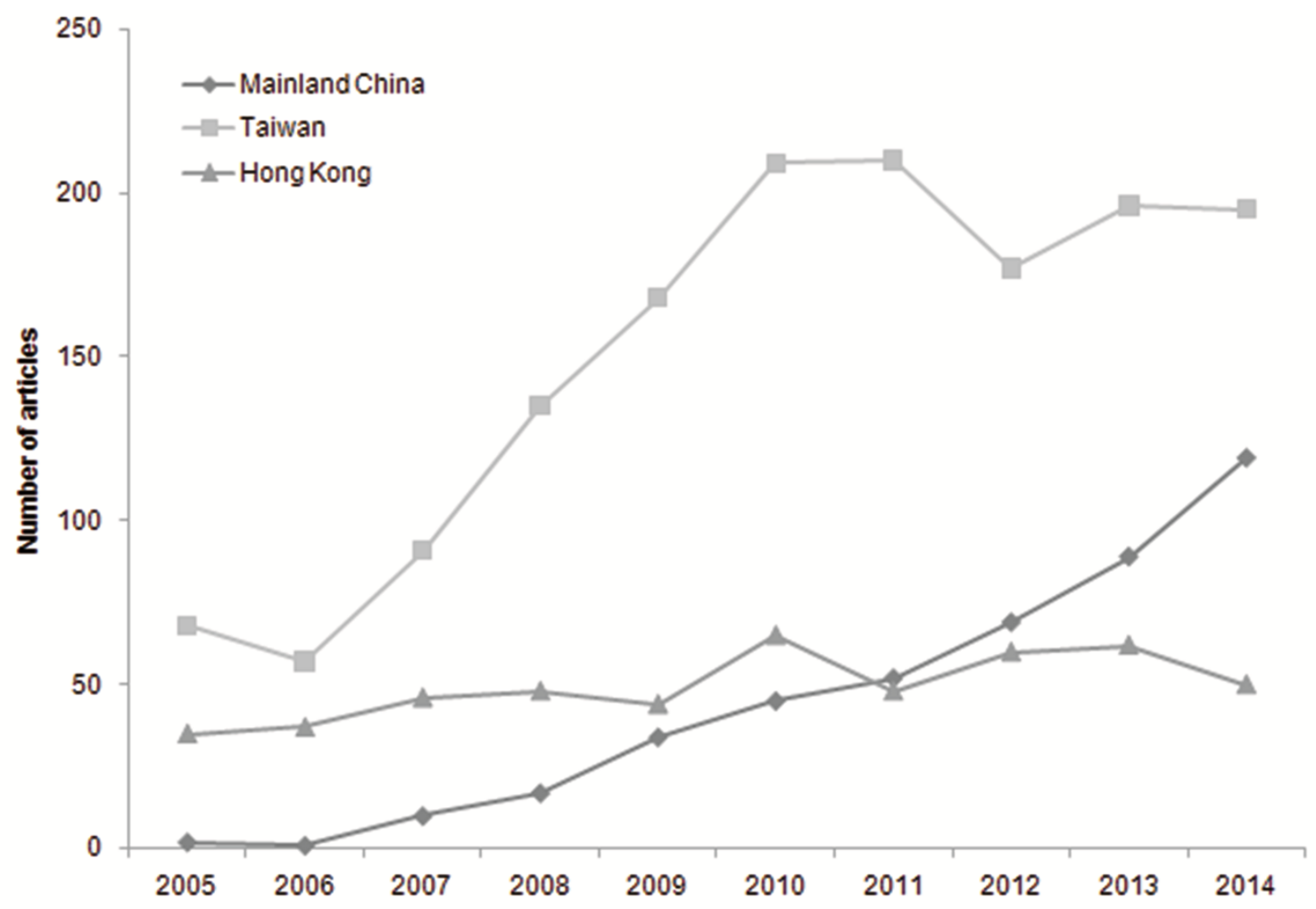

335

336

337

Figure 1 The number of articles from Mainland China, Taiwan, and Hong Kong in subspecialty nursing journals of 2014 Journal Citation Reports.

Table 1 Total and mean impact factor of articles from Mainland China, Taiwan, and Hong Kong

\begin{tabular}{rrrrrrrrr}
\hline \multirow{2}{*}{ Year } & \multicolumn{3}{c}{ Total impact factor } & & \multicolumn{3}{c}{ Mean impact factor } \\
\cline { 2 - 5 } \cline { 6 - 8 } \cline { 6 - 8 } & Mainland China & Taiwan & Hong Kong & & Mainland China & Taiwan & Hong Kong \\
\hline 2005 & 3.71 & 104.80 & 50.17 & & 1.85 & 1.54 & 1.43 \\
2006 & 1.26 & 98.22 & 57.64 & & 1.26 & 1.72 & 1.56 \\
2007 & 13.52 & 136.66 & 71.06 & & 1.85 & 1.50 & 1.54 \\
2008 & 21.53 & 200.38 & 69.33 & & 1.27 & 1.48 & 1.44 \\
2009 & 46.64 & 238.29 & 60.56 & & 1.37 & 1.42 & 1.38 \\
2010 & 65.87 & 307.73 & 101.24 & & 1.46 & 1.47 & 1.56 \\
2011 & 74.07 & 296.70 & 70.35 & & 1.42 & 1.41 & 1.47 \\
2012 & 93.76 & 243.55 & 83.21 & & 1.36 & 1.38 & 1.39 \\
2013 & 112.08 & 260.92 & 89.25 & & 1.26 & 1.33 & 1.44 \\
2014 & 151.52 & 255.56 & 67.59 & & 1.27 & 1.31 & 1.35
\end{tabular}




\begin{tabular}{lllllll} 
Total & 583.94 & 2142.81 & 720.39 & 1.33 & 1.42 & 1.46 \\
\hline
\end{tabular}

339

340

Table 2 Total and mean citation of articles from Mainland China, Taiwan, and Hong Kong

\begin{tabular}{rrrrrrrrr}
\hline \multirow{2}{*}{ Year } & \multicolumn{3}{c}{ Total citation } & & \multicolumn{3}{c}{ Mean citation } \\
\cline { 2 - 5 } \cline { 6 - 8 } & Mainland China & Taiwan & Hong Kong & & Mainland China & Taiwan & Hong Kong \\
\hline 2005 & 28 & 950 & 607 & & 14.00 & 13.97 & 17.34 \\
2006 & 28 & 732 & 436 & & 28.00 & 12.84 & 11.78 \\
2007 & 174 & 1040 & 609 & & 17.40 & 11.43 & 13.24 \\
2008 & 151 & 1417 & 577 & & 8.88 & 10.50 & 12.02 \\
2009 & 256 & 1159 & 505 & & 7.53 & 6.90 & 11.48 \\
2010 & 201 & 1261 & 490 & & 4.47 & 6.03 & 7.54 \\
2011 & 195 & 995 & 227 & & 3.75 & 4.74 & 4.73 \\
2012 & 274 & 481 & 185 & & 3.97 & 2.72 & 3.08 \\
2013 & 127 & 255 & 133 & & 1.43 & 1.30 & 2.15 \\
2014 & 59 & 102 & 16 & & 0.50 & 0.52 & 0.32 \\
Total & 1493 & 8392 & 3785 & & 3.41 & 5.57 & 7.65 \\
\hline
\end{tabular}

341

342

343

344

345

346

347

348

349 
Table 3 Articles published in the 10 top-ranking worldwide journals from Mainland China, Taiwan, and Hong Kong

\begin{tabular}{|c|c|c|c|c|c|c|}
\hline Rank & Journal & Impact factor & Mainland China & Taiwan & Hong Kong & Total \\
\hline 1 & International Journal of Nursing Studies & 2.901 & 22 & 132 & 37 & 191 \\
\hline 2 & Oncology Nursing Forum & 2.788 & 1 & 8 & 2 & 11 \\
\hline 3 & Worldviews on Evidence-Based Nursing & 2.381 & 0 & 9 & 1 & 10 \\
\hline 4 & American Journal of Critical Care & 2.115 & 1 & 10 & 3 & 14 \\
\hline 5 & Journal of Cardiovascular Nursing & 2.053 & 6 & 12 & 3 & 21 \\
\hline 6 & Journal of Human Lactation & 1.985 & 4 & 2 & 2 & 8 \\
\hline 7 & Cancer Nursing & 1.966 & 17 & 64 & 19 & 100 \\
\hline 8 & International Journal of Mental Health Nursing & 1.950 & 5 & 2 & 3 & 10 \\
\hline 9 & European Journal of Cardiovascular Nursing & 1.876 & 0 & 5 & 1 & 6 \\
\hline 10 & Journal of Advanced Nursing & 1.741 & 30 & 148 & 78 & 256 \\
\hline Total & & & 86 & 392 & 149 & 627 \\
\hline
\end{tabular}


Table 4 The 5 most popular nursing journals in Mainland China, Taiwan, and Hong Kong

\begin{tabular}{|c|c|c|c|c|c|c|}
\hline $\begin{array}{l}\text { Ran } \\
\mathrm{k}\end{array}$ & Mainland China & $\mathrm{N}$ & Taiwan & $\mathrm{N}$ & Hong Kong & $\mathrm{N}$ \\
\hline 1 & & & & 39 & & 14 \\
\hline & Journal of Clinical Nursing & 74 & Journal of Clinical Nursing & 2 & Journal of Clinical Nursing & 6 \\
\hline 2 & & & & 16 & & \\
\hline & Journal of Advanced Nursing & 30 & Journal of Nursing Research & 7 & Journal of Advanced Nursing & 78 \\
\hline 3 & International Journal of Nursing & & & 14 & International Journal of Nursing & \\
\hline & Studies & 22 & Journal of Advanced Nursing & 8 & Studies & 37 \\
\hline 4 & & & International Journal of Nursing & 13 & & \\
\hline & Nurse Education Today & 18 & Studies & 2 & Nurse Education Today & 29 \\
\hline 5 & Cancer Nursing & 17 & Cancer Nursing & 64 & Cancer Nursing & 19 \\
\hline Tota & & 17 & & 95 & & 32 \\
\hline 1 & & 8 & & 2 & & 8 \\
\hline
\end{tabular}

359 


\section{Table 1 (on next page)}

Table 1

Table 1 Total and mean impact factor of articles from Mainland China, Taiwan, and Hong

Kong 
Table 1 Total and mean impact factor of articles from Mainland China, Taiwan, and Hong Kong

\begin{tabular}{|c|c|c|c|c|c|c|}
\hline \multirow{2}{*}{ Year } & \multicolumn{3}{|c|}{ Total impact factor } & \multicolumn{3}{|c|}{ Mean impact factor } \\
\hline & Mainland China & Taiwan & Hong Kong & Mainland China & Taiwan & Hong Kong \\
\hline 2005 & 3.71 & 104.80 & 50.17 & 1.85 & 1.54 & 1.43 \\
\hline 2006 & 1.26 & 98.22 & 57.64 & 1.26 & 1.72 & 1.56 \\
\hline 2007 & 13.52 & 136.66 & 71.06 & 1.85 & 1.50 & 1.54 \\
\hline 2008 & 21.53 & 200.38 & 69.33 & 1.27 & 1.48 & 1.44 \\
\hline 2009 & 46.64 & 238.29 & 60.56 & 1.37 & 1.42 & 1.38 \\
\hline 2010 & 65.87 & 307.73 & 101.24 & 1.46 & 1.47 & 1.56 \\
\hline 2011 & 74.07 & 296.70 & 70.35 & 1.42 & 1.41 & 1.47 \\
\hline 2012 & 93.76 & 243.55 & 83.21 & 1.36 & 1.38 & 1.39 \\
\hline 2013 & 112.08 & 260.92 & 89.25 & 1.26 & 1.33 & 1.44 \\
\hline 2014 & 151.52 & 255.56 & 67.59 & 1.27 & 1.31 & 1.35 \\
\hline Total & 583.94 & 2142.81 & 720.39 & 1.33 & 1.42 & 1.46 \\
\hline
\end{tabular}

2 


\section{Table 2 (on next page)}

Table 2

Table 2 Total and mean citation of articles from Mainland China, Taiwan, and Hong Kong 
Table 2 Total and mean citation of articles from Mainland China, Taiwan, and Hong Kong

\begin{tabular}{|c|c|c|c|c|c|c|}
\hline \multirow{2}{*}{ Year } & \multicolumn{3}{|c|}{ Total citation } & \multicolumn{3}{|c|}{ Mean citation } \\
\hline & Mainland China & Taiwan & Hong Kong & Mainland China & Taiwan & Hong Kong \\
\hline 2005 & 28 & 950 & 607 & 14.00 & 13.97 & 17.34 \\
\hline 2006 & 28 & 732 & 436 & 28.00 & 12.84 & 11.78 \\
\hline 2007 & 174 & 1040 & 609 & 17.40 & 11.43 & 13.24 \\
\hline 2008 & 151 & 1417 & 577 & 8.88 & 10.50 & 12.02 \\
\hline 2009 & 256 & 1159 & 505 & 7.53 & 6.90 & 11.48 \\
\hline 2010 & 201 & 1261 & 490 & 4.47 & 6.03 & 7.54 \\
\hline 2011 & 195 & 995 & 227 & 3.75 & 4.74 & 4.73 \\
\hline 2012 & 274 & 481 & 185 & 3.97 & 2.72 & 3.08 \\
\hline 2013 & 127 & 255 & 133 & 1.43 & 1.30 & 2.15 \\
\hline 2014 & 59 & 102 & 16 & 0.50 & 0.52 & 0.32 \\
\hline Total & 1493 & 8392 & 3785 & 3.41 & 5.57 & 7.65 \\
\hline
\end{tabular}

2 


\section{Table 3(on next page)}

Table 3

Table 3 Articles published in the 10 top-ranking worldwide journals from Mainland China, Taiwan, and Hong Kong 
Table 3 Articles published in the 10 top-ranking worldwide journals from Mainland China, Taiwan, and Hong Kong

\begin{tabular}{|c|c|c|c|c|c|c|}
\hline Rank & Journal & Impact factor & Mainland China & Taiwan & Hong Kong & Total \\
\hline 1 & International Journal of Nursing Studies & 2.901 & 22 & 132 & 37 & 191 \\
\hline 2 & Oncology Nursing Forum & 2.788 & 1 & 8 & 2 & 11 \\
\hline 3 & Worldviews on Evidence-Based Nursing & 2.381 & 0 & 9 & 1 & 10 \\
\hline 4 & American Journal of Critical Care & 2.115 & 1 & 10 & 3 & 14 \\
\hline 5 & Journal of Cardiovascular Nursing & 2.053 & 6 & 12 & 3 & 21 \\
\hline 6 & Journal of Human Lactation & 1.985 & 4 & 2 & 2 & 8 \\
\hline 7 & Cancer Nursing & 1.966 & 17 & 64 & 19 & 100 \\
\hline 8 & International Journal of Mental Health Nursing & 1.950 & 5 & 2 & 3 & 10 \\
\hline 9 & European Journal of Cardiovascular Nursing & 1.876 & 0 & 5 & 1 & 6 \\
\hline 10 & Journal of Advanced Nursing & 1.741 & 30 & 148 & 78 & 256 \\
\hline Total & & & 86 & 392 & 149 & 627 \\
\hline
\end{tabular}

2 


\section{Table 4(on next page)}

Table 4

Table 4 The 5 most popular nursing journals in Mainland China, Taiwan, and Hong Kong 
Table 4 The 5 most popular nursing journals in Mainland China, Taiwan, and Hong Kong

\begin{tabular}{|c|c|c|c|c|c|c|}
\hline $\begin{array}{l}\text { Ran } \\
\mathrm{k}\end{array}$ & Mainland China & $\mathrm{N}$ & Taiwan & $\mathrm{N}$ & Hong Kong & $\mathrm{N}$ \\
\hline 1 & & & & 39 & & 14 \\
\hline & Journal of Clinical Nursing & 74 & Journal of Clinical Nursing & 2 & Journal of Clinical Nursing & 6 \\
\hline 2 & & & & 16 & & \\
\hline & Journal of Advanced Nursing & 30 & Journal of Nursing Research & 7 & Journal of Advanced Nursing & 78 \\
\hline 3 & International Journal of Nursing & & & 14 & International Journal of Nursing & \\
\hline & Studies & 22 & Journal of Advanced Nursing & 8 & Studies & 37 \\
\hline 4 & & & International Journal of Nursing & 13 & & \\
\hline & Nurse Education Today & 18 & Studies & 2 & Nurse Education Today & 29 \\
\hline 5 & Cancer Nursing & 17 & Cancer Nursing & 64 & Cancer Nursing & 19 \\
\hline Tota & & 17 & & 95 & & 32 \\
\hline 1 & & 8 & & 2 & & 8 \\
\hline
\end{tabular}




\section{1}

Figure 1

Figure 1 The number of articles from Mainland China, Taiwan, and Hong Kong in subspecialty nursing journals of 2014 Journal Citation Reports.

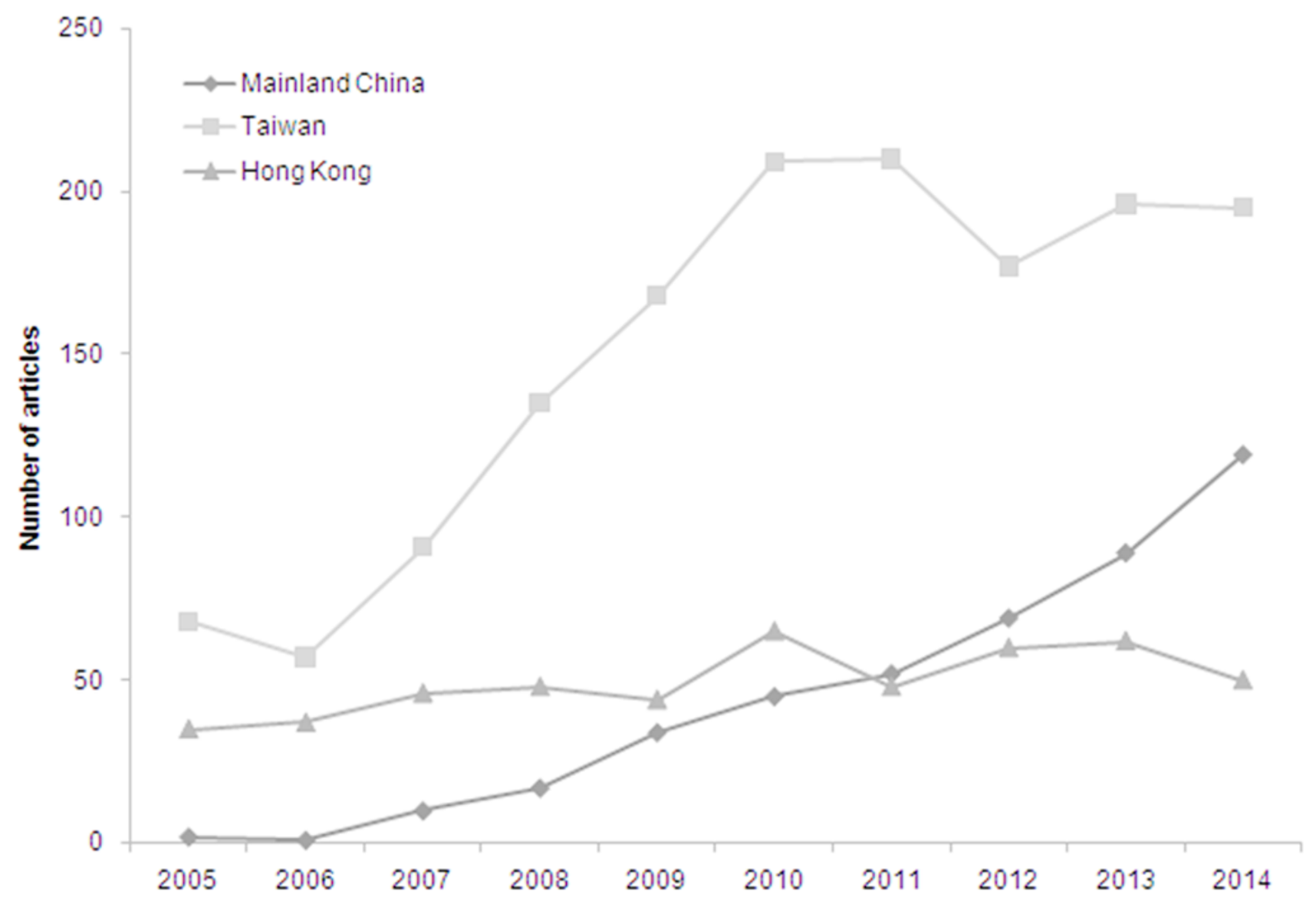

